\title{
A LÍNGUA \\ INGLESA \\ NA BNCC: \\ UMA ANÁLISE \\ DAS CONCEPÇÕES \\ DE LÍNGUA
}

\section{EL IDIOMA INGLÉS EN BNCC: UN ANÁLISIS DE LAS CONCEPCIONES DEL LENGUAJE}

\author{
THE ENGLISH LANGUAGE IN BNCC: AN ANALYSIS OF THE CONCEPTIONS OF LANGUAGE
}

\section{Marília Camponogara Torres* \\ Mariana Lima Terres**}

Universidade Federal de Santa Catarina

\begin{abstract}
RESUMO: Este estudo teve como objetivo analisar quais são as concepções de língua presentes no componente curricular Língua Inglesa do Ensino Fundamental propostas pela Base Nacional Comum Curricular (BNCC). Para isso, adotou-se uma abordagem qualitativa por meio da análise de excertos que versavam sobre língua. As concepções que embasaram a análise foram baseadas nas entrevistas de Salomão, Castilho, Geraldi e Rajagopalan (XAVIER; CORTEZ, 2003), os quais entendem a língua como expressão do pensamento, instrumento de comunicação, processo de interação e bandeira política, respectivamente. Como resultado, foi observada principalmente uma coocorrência de duas diferentes concepções de língua nos excertos analisados da Base - como interação e bandeira política. Dessa forma, considera-se essencial uma reavaliação do conceito de língua dos documentos norteadores do ensino de língua inglesa, garantindo uma melhor orientação dos currículos escolares e promovendo a educação básica de forma igualitária em todo país.
\end{abstract}

PALAVRAS-CHAVE: BNCC. Concepções de língua. Língua Inglesa

RESUMEN: Este estudio tuvo como objetivo analizar qué concepciones de lengua están presentes en el componente curricular Inglés de la Enseñanza Primaria propuesto por la Base Nacional Común Curricular (BNCC). Para esto, se adoptó un enfoque cualitativo a través del análisis de extractos relacionados con el lenguaje. Las concepciones que respaldaron el análisis se basaron en las entrevistas de Salomão, Castilho, Geraldi y Rajagopalan (XAVIER; CORTEZ, 2003). Estos investigadores entienden el lenguaje como expresión de pensamiento, herramienta de comunicación, proceso de interacción y bandera política,

\footnotetext{
* Graduada em Letras Português-Inglês pela Universidade Tecnológica Federal do Paraná (UTFPR), Mestra em Inglês: Estudos Linguísticos e Literários pela Universidade Federal de Santa Catarina (UFSC), Doutoranda em Estudos Linguísticose Literários também pela UFSC e Bolsistada Capes. E-mail: mariliactorres@gmail.com.

** Graduada em Letras Português-Inglês pela Universidade Federal de Pelotas (UFPEL), Mestra em Inglês: Estudos Linguísticos e Literários pela Universidade Federal de Santa Catarina (UFSC), Doutoranda em Estudos Linguísticos e Literários também pela UFSC e Bolsistada Capes. E-mail: mariana.terres@gmail.com.
} 
respectivamente. Los resultados indicaron una presencia simultánea de dos conceptos de lenguaje diferentes en los extractos de la Base - como interacción y bandera política. Así pues, es esencial una reevaluación de los documentos que rigen la enseñanza del idioma inglés sobre el concepto de lengua para garantizar una mejor orientación de los programas de estudios y promover la educación básica por igual en todo el país.

PALABRAS CLAVE: BNCC. Concepciones de lengua. Inglés.

ABSTRACT: This study aimed to analyze which conceptions of language are present in the English Language curriculum component of Elementary School proposed by the National Common Curricular Base (BNCC). For this, a qualitative approach was adopted through the analysis of excerpts that dealt with language. The conceptions of language that supported the analysis were based on the interviews of Salomão, Castilho, Geraldi and Rajagopalan (XAVIER; CORTEZ, 2003). These researchers understand language as an expression of thought, an instrument of communication, an interaction process, and a political flag, respectively. As a result, it was observed the co-occurrence of two different language conceptions in the Base extracts analyzed language as interaction and as a political flag. Thus, it is considered essential to reassess the guiding documents of English language teaching regarding the concept of language, ensuring a better orientation of school curricula and promoting basic education equally throughout the country.

KEYWORDS: BNCC. Conceptions of language. English.

\section{INTRODUÇÃO}

A criação de uma Base Nacional Curricular (BNCC) para auxiliar a construção de currículos escolares tem sido amplamente discutida por órgãos governamentais desde o início dos anos 1990 (GONTIJO, 2015). Em dezembro de 2017, sua última versão foi homologada pelo Conselho Nacional de Educação (CNE) com o objetivo de democratizar a educação básica do país e torná-la mais igualitária. A homologação desse documento de caráter normativo suscita ações de cunho político relativas à língua e aos interesses de poder nelas envolvidos. As razões para essa ocorrência são devido à língua estar estreitamente relacionada com a sociedade e a cultura, além da importância de se elaborar políticas alinhadas com o contexto globalizado no qual os alunos estão hoje inseridos (ROCHA; DIEZ, 2018).

Concepções de língua têm sido constantemente citadas em documentos e em orientações oficiais que objetivam desenvolver políticas públicas para o ensino de línguas estrangeiras nas escolas do país. Desse modo, torna-se relevante investigar essas concepções uma vez que dentre as principais mudanças instituídas pela Base está a obrigatoriedade da língua inglesa para o Ensino Fundamental II, do $6^{\circ}$ ao $9^{\circ}$ ano, em todo o território nacional (BRASIL, 2017). Essa ação é fundamentada, segundo Rocha e Diez (2018, p. 2), “[...] pelo seu uso global como língua franca como instrumento de comunicação intercultural entre povos de diferentes línguas e culturas em meio ao contexto multicultural da pós-modernidade”.

Com base nesse contexto, este artigo tem como objetivo analisar a concepção de língua presente na última versão da BNCC (BRASIL, 2017), mais especificamente em relação à Língua Inglesa como componente curricular no Ensino Fundamental. Foi escolhida apenas a seção do Ensino Fundamental em detrimento daquela do Ensino Médio, pois a primeira contém uma explicação mais detalhada do viés que é assumido para a língua inglesa. Para isso, foi adotada uma abordagem qualitativa (DÖRNYEI, 2007), a qual consistiu em selecionar excertos da BNCC que versavam sobre concepções de língua. Para as análises, baseou-se nas definições de língua de quatro pesquisadores: Salomão, Castilho, Geraldi e Rajagopalan, presentes na obra organizada por Xavier e Cortez (2003), além de outros autores, como Volochínov (2018), Geraldi (1984) e Lyotard (2018).

A fim de atender ao objetivo do estudo, este artigo se organiza da seguinte forma, após esta breve introdução: primeiramente, é feita uma descrição da BNCC, destacando alguns momentos históricos e as pesquisas já realizadas com base em seu documento, além de apresentar a Língua Inglesa como componente curricular; em seguida, são explicitadas as concepções de língua adotadas para a análise do presente estudo; a seção seguinte faz a análise dos excertos do documento no que se refere aos conceitos de língua dentro do ensino de língua inglesa; e, por fim, seguem as considerações finais e as referências. 


\section{A BNCC E O COMPONENTE CURRICULAR LÍNGUA INGLESA}

A BNCC foi criada com intuito de estabelecer a reunião das aprendizagens fundamentais que devem ser desenvolvidas por todos os alunos ao longo da Educação Básica. É um documento de natureza normativa que, de acordo com o seu site, objetiva destacar e indicar a qualidade do sistema educacional brasileiro através da determinação de um nível de aprendizagem e desenvolvimento que é direito de todos os estudantes. De acordo com a Lei de Diretrizes e Bases da Educação Nacional (LDB, Lei nº 9.394/1996), a BNCC precisa orientar os currículos dos sistemas de ensino das Unidades Federativas bem como as propostas pedagógicas de escolas públicas e privadas do Ensino Infantil, Fundamental e Médio, em todo território brasileiro. Além disso, conforme descrito no site:

\footnotetext{
A Base estabelece conhecimentos, competências e habilidades que se espera que todos os estudantes desenvolvam ao longo da escolaridade básica. Orientada pelos princípios éticos, políticos e estéticos traçados pelas Diretrizes Curriculares Nacionais da Educação Básica, a Base soma-se aos propósitos que direcionam a educação brasileira para a formação humana integral e para a construção de uma sociedade justa, democrática e inclusiva. (BRASIL, paginação irregular)
}

Para compreender melhor o surgimento e a finalidade da BNCC, alguns momentos históricos precisam ser destacados. Primeiramente, a Constituição da República Federal do Brasil de 1988 já havia previsto a criação da BNCC em seu Artigo 210. Oito anos mais tarde, foi aprovada a Lei de Diretrizes e Bases da Educação Nacional (LDBEN), Lei 9.394 que, em seu Artigo 26, tem por objetivo regulamentar uma base nacional comum para a Educação Básica do país. Nos anos 1997, 1998 e 2000 foram lançados os Parâmetros Curriculares Nacionais (PCNs) para os Ensinos Fundamental e Médio, com o intuito de assessorar as instituições educacionais a executarem suas atividades e a orientarem o desenvolvimento curricular.

As Diretrizes Curriculares Nacionais Gerais para a Educação Infantil, o Ensino Fundamental e o Ensino Médio foram definidas entre 2010 e 2012. O Plano Nacional de Educação (PNE) foi regulamentado em 2014 pela Lei 13.005, a qual apresentou metas para o melhoramento da qualidade da Educação Básica. A primeira versão do BNCC foi liberada em 2015 e disponibilizada para que as escolas pudessem apreciá-la e discuti-la. Sua segunda versão foi disponibilizada em 2016 e sofreu uma nova consulta popular para que, finalmente, uma terceira versão fosse elaborada. A versão final da BNCC da Educação Infantil e do Ensino Fundamental foi homologada em dezembro de 2017 e o Conselho Nacional da Educação (CNE) propôs por meio da Resolução CNE/CP n 2 a implantação do documento. Já a versão final do documento do Ensino Médio foi entregue em abril de 2018 e, em dezembro de 2018, foi homologada, instituindo, assim, uma Base com as aprendizagens previstas para todo o Ensino Básico.

Desde suas fases preliminares, a BNCC tem sido foco de inúmeros estudos na área da educação, abrangendo a análise de componentes curriculares como Educação Física (MARTINELI et al., 2016; NEIRA; SOUZA JUNIOR, 2016), História (JÚNIOR, 2016; COELHO; BELCHIOR, 2017); Geografia (GIROTTO, 2016), Física (MOZENA; OSTERMANN, 2016), Língua Portuguesa (AZEVEDO; DAMACENO, 2017), Língua Inglesa (ROCHA; DIEZ, 2018; FISTAROL; FISCHER; WENDERLICH, 2019; MALLMANN, 2018), Ciências, Química (LEITE; RITTER, 2017), entre outros. Além disso, a BNCC também foi analisada em termos do papel das tecnologias digitais (HEINSFELD; SILVA, 2018) e do conceito de diversidade contido em seu texto (FERREIRA, 2015).

Outros estudos importantes na área foram: Correa (2016), Silva (2018), Micarello (2016) e Triches e Aranda (2016). O primeiro faz um balanço do impacto da primeira versão da BNCC através de um esboço esquemático parcial com uma breve avaliação da segunda versão. Silva (2018), por sua vez, analisa o discurso apresentado nas propostas e reformas da BNCC e como ele está conectado com os antigos discursos que sustentaram a educação básica do país nos últimos 20 anos. Já Micarello (2016) avalia o processo de elaboração da BNCC em referência ao contexto político atual e como as diferentes posições e opiniões na produção da segunda versão do documento foram organizadas. Por último, Triches e Aranda (2016) focam nos discursos de organismos oficiais e de publicações de revistas científicas sobre a BNCC.

Forum lingüístic., Florianópolis, v.18,n.3,p.6466-6478, jul./set.2021 
Além desses estudos, Neira, Júnior e Almeida (2016), Gontijo (2015) e Silva (2015) também trazem contribuições para melhor compreender a BNCC. Neira, Souza Júnior e Almeira (2016) narram as etapas do processo de criação e principais influências das duas primeiras versões da BNCC a partir do ponto de vista de um participante envolvido no processo de produção. Gontijo (2015), por seu turno, busca entender a proposta de língua portuguesa para os primeiros anos do ensino fundamental, focando no processo de alfabetização concretizada no documento e em seus aspectos conceituais. Por fim, Silva (2015) questiona as relações entre políticas curriculares, o ensino médio e a BNCC através do debate do caráter conceitual sobre educação, formação humana e currículo desde 1996 até os dias atuais.

No que concerne à materialidade da BNCC, seu documento possui aproximadamente 600 páginas e cinco capítulos divididos em introdução, estrutura da BNCC, Educação Infantil, Ensino Fundamental e Ensino Médio. O capítulo introdutório apresenta a Base e suas competências, os marcos legais balizadores, os fundamentos pedagógicos, o pacto interfederativo e a implementação do documento. O segundo capítulo descreve a estrutura geral da BNCC em relação às três etapas da Educação Básica: Educação Infantil, Ensino Fundamental e Ensino Médio. Além disso, o capítulo explica como as aprendizagens estão estruturadas em cada uma das fases e esclarece a estruturação dos códigos alfanuméricos elaborados para identificar cada objetivo de aprendizagem e desenvolvimento. O terceiro capítulo apresenta a etapa da Educação Infantil, os direitos de aprendizagem e desenvolvimento, os campos de experiências, os objetivos de aprendizagem e a transição para o ensino fundamental. O capítulo quatro descreve a etapa do Ensino Fundamental, dividindo-a em cinco áreas - Linguagens, Matemática, Ciências da Natureza, Ciências Humanas e Ensino Religioso. O último capítulo, após introduzir a BNCC no contexto do Ensino Médio e os currículos da Base e itinerários, divide-se em área de Linguagens e suas Tecnologias, área de Matemática e suas Tecnologias, área de Ciências da Natureza e suas Tecnologias e área de Ciências Humanas e Sociais Aplicadas.

A Língua Inglesa, foco do presente estudo, está dentro da área de Linguagens na BNCC, a qual também é composta pelos seguintes componentes curriculares: Língua Portuguesa, Arte e Educação Física. No Ensino Fundamental, como já mencionado, o ensino do inglês está presente obrigatoriamente nos anos finais (do $6^{\circ}$ ao $9^{\circ}$ ano), enquanto no Ensino Médio também é de caráter obrigatório, porém os anos nos quais deve ser lecionado não são mencionados. A seção do componente curricular Língua Inglesa descrita no Ensino Fundamental contém em seu texto a finalidade do idioma, as implicações, os eixos organizadores, as competências específicas, as unidades temáticas, os objetos de conhecimento e as habilidades. Esses três últimos conteúdos também estão presentes na seção do Ensino Médio, já os outros são apenas brevemente referenciados, pois já foram explicitados anteriormente no documento no Ensino Fundamental. Dessa forma, primou-se pela análise da Língua Inglesa no Ensino Fundamental justamente por apresentar uma descrição mais extensa.

\section{CONCEPÇÕES DE LÍNGUA}

Pensar o ensino da língua inglesa como língua estrangeira, quer seja na prática docente ou nos documentos oficiais, como é o caso da BNCC, significa também pensar nas concepções de língua subjacentes. Para isso, torna-se necessário analisar quatro concepções e suas implicações, as quais tiveram e ainda exercem papel relevante no ensino. Apesar de três serem as principais tendências difundidas para explicar o conceito de língua (VOLOCHÍNOV, 2018; GERALDI, 1984), foi adicionada a esta discussão uma quarta, pautada na subdivisão existente entre modernidade e pós-modernidade para a Linguística Aplicada (MOITA LOPES, 2009).

Segundo Volochínov (2018), as três principais tendências da ciência da linguagem que abordam conceitos de língua são: o subjetivismo individualista, o objetivismo abstrato e a interação verbal. Com relação a esses termos, Geraldi (1984) refere-se a eles como língua como expressão do pensamento, instrumento de comunicação e processo de interação. Como representantes contemporâneos, tem-se Salomão, Castilhos e Geraldi (XAVIER; CORTEZ, 2003), representando cada uma das tendências respectivamente, os quais serão aqui abordados para conceituar língua.

Para a primeira tendência, o subjetivismo individualista, a língua seria concebida como a expressão do pensamento, sendo, portanto, considerada individual, monológica e consciente (VOLOCHÍNOV, 2018). Alinhada à essa noção, Salomão (XAVIER;

Torres \& Terres $\mid$ A língua inglesa na BNCC: uma análise das concepçóes de língua 
CORTEZ, 2003) a conceitua como uma capacidade cognitiva que possibilita ao ser humano representar o mundo para si e para os outros. Uma vez que essa capacidade é cognitiva, a língua teria um vínculo com o pensamento, sendo a sua manifestação uma representação desse. Ademais, segundo essa pesquisadora, a língua tem o papel de definidora da condição humana, ou seja, é ela quem determina o status quo do ser humano.

Já na segunda, o objetivismo abstrato, a língua é vista como um sistema com elementos fonéticos, gramaticais e lexicais. Segundo Volochínov (2018), Saussure foi um dos representantes mais significativos dessa concepção. Para ele, existiria uma distinção entre língua e linguagem, sendo a última heterogênea e sem uma unidade interior, enquanto a primeira seria uniforme e pertencente a todos. Desse modo, somente a língua poderia ser considerada objeto de estudo da Linguística por ser um sistema de signos que se combinam entre si segundo regras normativas linguísticas, os quais são transferidos de uma geração para a outra (GERALDI, 1984; VOLOCHÍNOV, 2018).

Castilho (XAVIER; CORTEZ, 2003), ao conceituar língua, está mais próximo dessa segunda concepção uma vez que ele a define como multissistêmica: haveria na língua um sistema lexical associado aos sistemas semântico, discursivo e sintático, tal como o objetivismo abstrato argumentava sobre o conceito de língua. Ainda segundo o professor, nas línguas existiria um dispositivo central e pré-verbal que antecede e governa a execução linguística, chamado por ele de sociocognitivo, responsável por ativar as propriedades lexicais nos três sistemas relacionados a elas. Esse sistema, por sua vez, seria social, na medida em que ele funciona na interação social, e cognitivo, pois atua com categorias cognitivas.

Volochínov (2018) critica essas duas tendências, argumentando que elas não suprem o caráter social inerente à língua. Dessa forma, segundo ele, não é possível considerá-la como um sistema estável de formas normativas idênticas, conforme os pressupostos do objetivismo abstrato, pois isso não corresponde à sua realidade concreta, a menos que se tenha, para essa concepção, um fim bem específico e prático. Do mesmo modo, também não há como conceber a sua formação como individual e psicológica, preceito defendido pelo subjetivismo individualista, pois as leis de formação da língua são essencialmente sociológicas e não individuais. Sendo assim, Volochínov propõe uma terceira tendência: a língua como interação verbal.

Nessa concepção, ainda segundo o autor, a língua é entendida como um produto coletivo da atividade humana, contendo a organização econômica e sociopolítica da sociedade. Isso significa que, por ser construída historicamente na e pela atividade humana, ela é produto, criação e representação da vida social, surgindo nas/pelas relações sociais. É por meio da língua que são criados e formados não só os sistemas ideológicos (ciência, moral, direito, arte etc.), mas também a consciência individual do homem. Desse modo, depreende-se que a língua consiste em um processo ininterrupto em formação, realizado por meio da interação sócio-discursiva dos falantes.

Geraldi (XAVIER; CORTEZ, 2003), também defensor dessa terceira concepção, concebe a língua como processo de interação entre os indivíduos em um contexto comunicativo. Dessa forma, essa conceituação de língua destaca a relevância da interação para dar significado ao mundo, reconhecendo-a como social, histórica e coletiva. Além disso, ela também é instrumento e produto do trabalho social e histórico de uma comunidade e sua sistematização está sempre em aberto, pois, ao ser retomada por seus usuários, o que antes nela estava estabilizado se desestabiliza na concretude do discurso, nas trocas interativas de uso da língua. Nessa concepção, para que haja sociedade, deve haver língua, pois ela surge como parte do processo de construção da organização da sociedade e, ao mesmo tempo, como processo de construção do pensamento, ela exerce função de instrumento na produção de discursos. Desta forma, a língua, o pensamento, os sujeitos e a organização social estão estreitamente associados.

Até esse momento, com a terceira tendência, a língua era concebida como instrumento, essencial nas trocas de interação para estabelecer as relações humanas. No entanto, houve uma mudança na concepção de língua a partir do final dos anos 1950, com a chamada virada pós-moderna. Lyotard (2018) destaca que nessa época, com a crise nas ciências e nas instituições universitárias, passou-se a acreditar não haver mais diferença entre conhecimento e saber. Este último, de acordo com o pensamento moderno, consistia em um conjunto de conhecimentos que permitiam um cientista ou um filósofo proferir juízos de verdade, o que acabou por gerar inúmeros conflitos com os seus discursos dentro da ciência (LYOTARD, 2018). Já no pensamento pós-moderno, o saber

Forum lingüístic., Florianópolis, v.18,n. 3,p.6466-6478,jul./set.2021. 
passa a ser visto como relativizado e traduzível e não mais como universal e totalitário. Essa mudança de paradigma dá importância às trocas discursivas e percebe a língua como propulsora da cultura, surgindo a quarta concepção de língua.

Nessa última concepção, a língua deixa de ser entendida como instrumento e passa a ser o centro da atividade humana, a formadora da história, influenciando os modos de vidas dos sujeitos. De acordo com Rajagopalan (XAVIER; CORTEZ, 2003; SILVA; SANTOS; JUSTINA, 2011), a língua não pode ser enquadrada em uma visão teórica, pois ela influencia e é mediadora da vida diária, sendo uma bandeira política erguida conforme as conveniências políticas do indivíduo. Nesse sentido, a língua é mais do que é um código ou um instrumento de comunicação, pois ela é criada e ajustada enquanto nos comunicamos. Ela é, antes de mais nada, uma marca identitária de um indivíduo.

Com base nessas quatro concepções de língua explicitadas, apresentaremos e discutiremos, na seção seguinte, excertos extraídos do componente curricular Língua Inglesa da BNCC do Ensino Fundamental que versam sobre língua.

\section{OS CONCEITOS DE LÍNGUA NO COMPONENTE CURRICULAR LÍNGUA INGLESA DA BNCC}

Os trechos extraídos para análise neste artigo estão contidos entre as páginas 241 e 246 do documento da BNCC. Cabe ressaltar que não é objetivo do presente estudo analisar todos os pontos incluídos nessas páginas, mas apenas aqueles que abordam conceitos de língua. Foram excluídas também desta análise as seções contendo as unidades temáticas, os objetos de conhecimento e as habilidades que devem ser enfatizadas em cada ano escolar também pelo motivo de não conterem as definições do objeto de estudo. Os resultados encontrados serão apresentados e discutidos em relação aos trechos do documento acerca da finalidade da língua inglesa, suas implicações, seus eixos organizadores e suas competências específicas, sendo todos eles comparados com as concepções de língua explicitadas anteriormente.

No que concerne à finalidade da língua inglesa, o documento ressalta a importância do idioma para poder estabelecer novas formas de envolvimento dos alunos frente a um mundo plural e globalizado, onde as fronteiras se apresentam cada vez mais indefinidas e divergentes. Dessa forma, concebe o caráter formador do ensino da língua como essencial para possibilitar o acesso aos saberes linguísticos, com o intuito de propiciar a continuidade aos estudos, construir conhecimentos, aumentar a interação e a mobilidade, e permitir o agenciamento crítico dos alunos no exercício da cidadania ativa (BRASIL, 2017). A noção de língua, nesse trecho, ao ser compreendida não mais como pertencente a um determinado território, mas, sim, a todos os falantes, está alinhada com a concepção de língua pós-moderna, uma vez que ela enfoca o contexto globalizado no qual as fronteiras são difusas.

Nessa compreensão de língua trazida pela BNCC há uma breve introdução do conceito de língua franca, o qual justamente abarca a noção de desterritorialização da língua e será mais bem explicitado na primeira implicação, descrita em seguida. Ainda nesse trecho, ao adotar esse contexto para a língua inglesa, ela passa a ser considerada como uma forma de engajamento, de interação e de mobilidade entre seus falantes, fazendo-os agir e se posicionar politicamente e criticamente na sociedade (XAVIER; CORTEZ, 2003).

Ao abordar as finalidades do ensino do inglês, o documento destaca três implicações para o currículo escolar: o caráter formador, os multiletramentos e as abordagens de ensino; sendo que todas elas contêm conceitos de língua. A primeira implicação, seu caráter formador, diz respeito às relações entre língua, território e cultura, as quais precisam ser revistas ao conceber o status da língua inglesa como língua franca. Nessa perspectiva, como consta na BNCC,

[...] a língua inglesa não é mais aquela do "estrangeiro", oriundo de países hegemônicos, cujos falantes servem de modelo a ser seguido, nem tampouco trata-se de uma variante da língua inglesa. Nessa perspectiva, são acolhidos e legitimados os usos que dela fazem falantes espalhados no mundo inteiro, com diferentes repertórios linguísticos e culturais, o que possibilita, por exemplo, questionar a visão de que o único inglês "correto" - e a ser ensinado - é aquele falado por estadunidenses ou britânicos. Mais ainda, o tratamento do inglês como língua franca o desvincula da noção de pertencimento a um determinado território e, 
consequentemente, a culturas típicas de comunidades específicas, legitimando os usos da língua inglesa em seus contextos locais. (BRASIL, 2017, p. 241-242)

Ao mencionar que não há mais uma prevalência do inglês falado por falantes nativos, como aqueles provenientes dos Estados Unidos, da Irlanda e da Inglaterra, por exemplo, coloca-se justamente em foco o idioma utilizado por usuários que não têm a língua inglesa como língua materna, como ocorre no Brasil. Essa noção remonta aos três círculos do inglês, propostos por Kachru (1998).

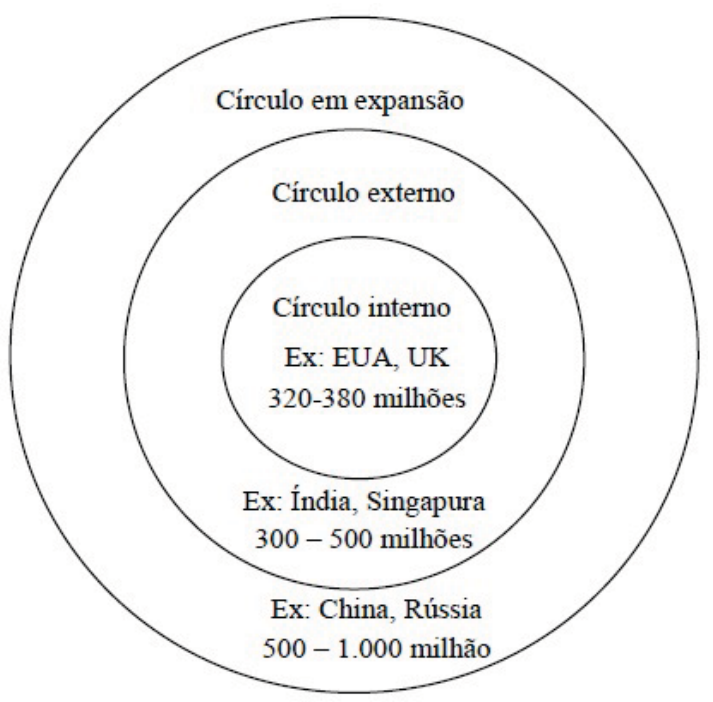

Figura 1: Os três círculos do inglês

Fonte: Kachru (1998 apud CRYSTAL, 2003, p. 61)

Esses círculos, na verdade, representam a expansão do inglês, mostrando que a língua inglesa é uma língua com três círculos de influência. Sendo assim, no círculo interno estão os países que têm o inglês como primeira língua (Estados Unidos, Reino Unido, Irlanda, Canadá, Austrália e Nova Zelândia). O círculo externo, por sua vez, abrange os locais em que o idioma desempenha um importante papel como segunda língua por alguma razão histórica ou cultural como é o caso de Singapura, Índia, Malawi, além de mais de 50 outros países. Por fim, no círculo em expansão estão os países que reconhecem a importância do inglês como língua internacional, apesar de não terem sido colonizados por membros do círculo interno (por exemplo, China, Rússia, Japão, Grécia, Polônia e, como o próprio círculo sugere, muitos outros, entre eles, o Brasil).

É nesse contexto do terceiro círculo que a BNCC parece estar pautada, uma vez que reconhece que não há um único modelo ou variante da língua a ser seguido, mas há vários usuários em diversos países que utilizam a língua para os mais variados fins, carregando consigo marcas linguísticas, culturais e identitárias. Além disso, ao adotar a perspectiva do inglês como língua franca, também se entende que não há mais posse/territorialidade da língua, pelo contrário, ela passa a ser de todos (JENKINS, 2000). Essa visão do inglês como língua franca assemelha-se com as características trazidas pela concepção de língua pós-moderna, na qual a língua é concebida como uma marca identitária e é ajustada conforme o seu contexto de uso e a sua finalidade. Da mesma maneira, Rajagopalan (2009) afirma que é importante pensar a língua inglesa desprendida do falante nativo hegemônico, pois ela não é propriedade de uma nação em particular. Na verdade, ela é policêntrica e caracteriza-se por ser um fenômeno linguístico que ainda está em atuação, abrindo espaço para refutações, subversões, insubordinações e reformulações.

Ainda acerca desse entendimento da língua inglesa como língua franca, a BNCC, em seu documento, ressalta que essa desterritorialização do idioma propicia a interculturalidade na educação linguística para que haja uma "[...] reflexão crítica sobre diferentes modos de ver e de analisar o mundo, o(s) outro(s) e a si mesmo" (BRASIL, 2017, p. 242). Apesar de o documento não conceituar interculturalidade, entende-se pelo termo um conjunto de situações comunicativas com interações socioculturais que instigam a legitimação e o respeito à cultura do outro, promovendo cordialidade entre indivíduos com diferentes culturas (ROCHA; DIEZ, 2018). Desse modo, ao adotar a concepção de língua franca no ensino da língua inglesa, a fim de que os 
estudantes possam refletir sobre a interculturalidade, a noção de língua equipara-se aqui mais uma vez à noção de língua pósmoderna.

Dando sequência à análise das implicações, a segunda, diferentemente da primeira, versa sobre os multiletramentos como práticas sociais e parece abordar uma concepção de língua como interação. Conforme explicitado no documento,

A segunda implicação diz respeito à ampliação da visão de letramento, ou melhor, dos multiletramentos, concebida também nas práticas sociais do mundo digital - no qual saber a língua inglesa potencializa as possibilidades de participação e circulação - que aproximam e entrelaçam diferentes semioses e linguagens (verbal, visual, corporal, audiovisual), em um contínuo processo de significação contextualizado, dialógico e ideológico. Concebendo a língua como construção social, o sujeito "interpreta", "reinventa" os sentidos de modo situado, criando novas formas de identificar e expressar ideias, sentimentos e valores. (BRASIL, 2017, p. 242)

Desse modo, percebe-se nesse trecho que a língua, em uma concepção multimodal, é concebida como uma construção social, ou seja, é na interação com o outro e na busca de sentidos que a sua realidade se constitui, conceitos esses trazidos pela segunda concepção de língua. Segundo Volochínov (2018), compreender língua como interação significa concebê-la em seu caráter histórico, social e ideológico, ligada de forma intrínseca às interações humanas. Por conter essas características, a língua está em constante formação em um processo ininterrupto, já que suas leis são sociológicas, considerando-se os valores e os sentidos ideológicos na interação entre os sujeitos. Desse modo, o documento, ao entender a língua como uma construção social e em contínua formação, aproxima-se da concepção de língua como interação.

Por último, a terceira implicação retoma as abordagens de ensino da língua inglesa como língua franca, o que requer um entendimento da relativização de determinadas crenças referentes a variantes da língua. No documento, não há priorização de variantes consideradas padrão, pelo contrário, objetiva-se a construção de um repertório linguístico expondo os usos locais da língua inglesa e os recursos linguísticos relativos a eles, descolados, portanto, de um modelo ideal para que, assim, os alunos possam utilizar os referidos recursos sob a condição de inteligibilidade na interação. As preocupações expostas pela BNCC são com a relevância da cultura no ensino-aprendizagem e com a busca pela extinção da valoração de aprender a falar o idioma conforme o falante nativo como é exposto no documento: "o status de inglês como língua franca implica deslocá-la de um modelo ideal de falante, considerando a importância da cultura no ensino-aprendizagem da língua e buscando romper com aspectos relativos à 'correção', 'precisão' e 'proficiência' linguística” (BRASIL, 2017, p. 242). Nesse excerto, pode-se observar características que se alinham com a quarta concepção de língua, inscrita na pós-modernidade. Quando o documento menciona a importância da relativização do saber, destacando que não se deve mais considerar uma variedade linguística como "melhor" ou "pior", ele se filia ao entendimento do saber do pensamento pós-moderno, que deslegitima a universalização do saber e concebe a língua como formadora da história e da cultura, estritamente influenciada pelos diferentes modos de vida dos sujeitos (LYOTARD, 2018).

Outra questão abordada neste trecho é a importância da inteligibilidade durante um evento comunicativo, deslegitimando mais uma vez o inglês nativo como o ideal e como objetivo principal do ensino da língua. A esse respeito, Celce-Murcia et al. (2010) enfatizam que muitas são as definições para a noção de inteligibilidade, sendo uma delas a habilidade de ouvintes e falantes em reconhecer palavras e segmentos. Além disso, o termo também engloba a presença de um sotaque, o que todos temos independente da variedade do idioma que falamos, desde que esse não distraia os envolvidos em uma situação comunicativa. Desse modo, ao considerar a inteligibilidade no ensino da língua inglesa, objetiva-se que os estudantes possam compreender e ser compreendidos em uma situação comunicativa de interação, podendo os interlocutores trazerem características identitárias para o seu discurso bem como modificá-lo conforme o contexto. Ao trazer esse conceito para o ensino da língua inglesa, o documento reitera sua afiliação à quarta concepção de língua inscrita na pós-modernidade, na qual não se admite uma variedade ideal a ser seguida, mas se reconhece a existência de diferentes falantes de vários lugares que usam a língua para inúmeros propósitos, trazendo em sua bagagem as marcas linguísticas, identitárias e culturais.

Em seguida, a BNCC apresenta cinco eixos organizadores para o ensino da Língua Inglesa no Ensino Fundamental: Oralidade, Leitura, Escrita, Conhecimentos Linguísticos e Dimensão Cultural. Cada um deles envolve práticas de linguagem de acordo com 
as suas particularidades. Entretanto, o documento destaca que, apesar de explicitar os eixos organizadores separadamente, eles devem ser tratados de forma interligada nos contextos sociais de uso do inglês e precisam ser trabalhados em conjunto nos diferentes modos de aprendizagem propostos na escola, sem que nenhum seja sobreposto aos demais, principalmente o eixo Conhecimentos Linguísticos. A esse respeito, o texto explica que a língua, por ser híbrida, polifônica e multimodal, é responsável por conduzir o estudo de suas próprias especificidades, não sendo possível considerar esse último eixo como pré-requisito para o seu estudo. Tendo em vista esse caráter híbrido, polifônico e multimodal defendido pela BNCC, pode-se dizer que ele se alinha com a terceira concepção de língua, pois a considera como um sistema em aberto que é desestabilizado constantemente, sendo formado por inúmeros discursos e moldado de acordo com contextos específicos (BAKHTIN, 2015; VOLOCHÍNOV, 2018). Além disso, ao considerar essa natureza híbrida e polifônica da língua, o documento passa a considerar o aluno como agente no processo comunicativo, e não como um mero reprodutor de modelos previamente estabelecidos e consolidados (GONÇALVES; BARONAS, 2013).

Os últimos trechos analisados neste estudo fazem parte da seção de competências específicas. No documento, há seis competências para o componente curricular Língua Inglesa para o Ensino Fundamental. Para fins práticos de análise, elas foram agrupadas de acordo com as concepções de língua com as quais se alinham. Foram excluídas dessa análise as competências 5 e 6 por não versarem sobre conceitos de língua. Sendo assim, as competências 1, 2 e 4 encontram-se em um mesmo grupo por indicarem uma maior relação com a concepção de língua como interação, sendo elas:

1. Identificar o lugar de si e o do outro em um mundo plurilíngue e multicultural, refletindo, criticamente, sobre como a aprendizagem da língua inglesa contribui para a inserção dos sujeitos no mundo globalizado, inclusive no que concerne ao mundo do trabalho.

2. Comunicar-se na língua inglesa, por meio do uso variado de linguagens em mídias impressas ou digitais, reconhecendo-a como ferramenta de acesso ao conhecimento, de ampliação das perspectivas e de possibilidades para a compreensão dos valores e interesses de outras culturas e para o exercício do protagonismo social.

4. Elaborar repertórios linguístico-discursivos da língua inglesa, usados em diferentes países e por grupos sociais distintos dentro de um mesmo país, de modo a reconhecer a diversidade linguística como direito e valorizar os usos heterogêneos, híbridos e multimodais emergentes nas sociedades contemporâneas. (BRASIL, 2017, p. 246, grifos nossos)

Nas competências 1 e 2, a língua demonstra ser concebida como uma ferramenta que garante acesso ao conhecimento e possibilita a inclusão social e no mercado de trabalho. Essa visão filia-se à terceira concepção de língua que a define como instrumento e produto da interação social, possibilitando a construção de sistemas ideológicos, de significação do mundo e do protagonismo social, ou seja, a língua como um sistema em constante reformulação através dos processos de interação social entre os falantes. Nessa concepção, segundo Geraldi, o pensamento, os indivíduos e a organização social estão intimamente conectados (XAVIER; CORTEZ, 2003).

Ademais, a BNCC, ao mencionar a língua como um fator que possibilita a inserção dos sujeitos em várias esferas sociais, incluindo o ambiente de trabalho, mais uma vez reitera a terceira concepção de língua. A esse respeito, Volochínov (2013) afirma que a língua se tornou uma condição fundamental para a organização do trabalho, cumprindo assim um papel na vida social. O mesmo ocorre em outras esferas sociais, nas quais é por meio da língua, adequando-a ao contexto, que os seres humanos estabelecem relações dialógicas de sentido, compreendendo nessa interação valores e aspectos culturais do outro (BAKHTIN, 2011).

Da mesma forma, a competência 4 também faz alusão à terceira concepção de língua. Nela, faz-se referência à língua como heterogênea, híbrida e multimodal, características essas presentes ao se considerar a língua em formação contínua, cujas leis são regidas na e pela interação sócio-discursiva dos falantes, em seu uso, dependendo do contexto no qual seus usuários estão inseridos (BAKHTIN, 2011; VOLOCHÍNOV, 2018). Além disso, por ser híbrida e heterogênea, uma língua está vinculada a outras, estabelecendo relações dialógicas e axiológicas na busca de sentido tanto na visão do falante quanto do ouvinte, que reconhece, desse modo, a sua língua e a do outro (BAKHTIN, 2011, 2015). 
Por fim, diferentemente dessas três competências anteriores, a competência 3 parece estar mais relacionada com a quarta concepção de língua, a qual afirma:

3. Identificar similaridades e diferenças entre a língua inglesa e a língua materna/outras línguas, articulando-as a aspectos sociais, culturais e identitários, em uma relação intrínseca entre língua, cultura e identidade. (BRASIL, 2017, p. 246, grifo nosso)

Essa competência, por sua vez, traz a relação da língua com a identidade e a cultura, a qual está mais relacionada com a concepção de língua franca. Conceber o inglês como uma língua franca, como já mencionado, significa transferir para o segundo idioma características da língua materna do falante, como o sotaque, por exemplo, o qual pode ser considerado um aspecto identitário. Nesse viés, ao não mais almejar a pronúncia de um falante nativo, os sujeitos imprimem, ao falar a língua inglesa como língua adicional, o seu modo de falar, com o objetivo de serem inteligíveis, fazendo com que haja uma relação entre língua, cultura e identidade. Acerca disso, Rajagopalan (XAVIER; CORTEZ, 2003) também considera a língua como uma bandeira política que os sujeitos erguem quando usam o idioma justamente por expressarem em seu uso as suas concepções políticas. Ou seja, há na língua relações de poder, identidade e cultura que os indivíduos trazem consigo ao se comunicar no idioma. Afinal, como defende o pesquisador, "linguagem somos nós" (XAVIER; CORTEZ, 2003, p. 180).

\section{CONCLUSÃO}

O presente artigo teve como objetivo analisar o que a última versão do documento da BNCC (BRASIL, 2017), homologada pelo CNE, define de língua no componente curricular Língua Inglesa, especificamente na seção do Ensino Fundamental. Como previamente enfatizado, optou-se por analisar o Ensino Fundamental em detrimento do Ensino Médio, pois este continha um conteúdo teórico mais resumido e referenciava as orientações descritas na seção do Ensino Fundamental como guias. Sendo assim, as concepções de língua encontradas no documento foram analisadas de acordo com quatro definições: subjetivismo individualista, objetivismo abstrato, interação verbal e a concepção de língua pós-moderna. Essas categorias foram baseadas em entrevistas com os pesquisadores Salomão, Castilho, Geraldi e Rajagopalan, as quais encontram-se na obra organizada por Xavier e Cortez (2003).

No documento, de maneira geral, é adotada uma visão de língua de caráter heterogêneo, considerando-a como variável e sóciohistoricamente heterogênea, como tem sido proposto atualmente pelos documentos oficiais que orientam o ensino de língua, não privilegiando somente a variedade considerada padrão, usada por classes sociais mais altas e por falantes nativos (GONÇALVES; BARONAS, 2013). Entretanto, a análise dos excertos do componente curricular Língua Inglesa para o Ensino Fundamental não demonstrou uma definição precisa a respeito da concepção de língua a ser difundida pelos currículos e adotada pelas escolas, e, sim, uma coocorrência de duas diferentes concepções de língua: as concepções de língua como interação verbal e a pós-moderna.

Com base nesses resultados, este estudo também traz algumas implicações pedagógicas para o ensino do componente curricular Língua Inglesa na educação básica. Uma vez que se observou principalmente a presença de duas concepções de linguagem na BNCC, torna-se relevante que os professores, ao ensinarem o idioma em sala de aula, propiciem atividades visando o uso da língua de forma interativa e contextual, bem como tendo como foco oportunidades para que haja a reflexão sobre quem são os falantes da língua. Dessa forma, é necessário que estejam presentes no contexto escolar diversas variantes da língua inglesa, tanto na oralidade quanto na escrita, para que os alunos percebam que a língua é de todos os que a usam, não havendo apenas um inglês, mas vários, cujos usuários, em uma situação comunicativa, objetivam a inteligibilidade.

Ademais, ressalta-se também a importância de se reavaliar os documentos norteadores do ensino de inglês, com o intuito de se utilizar uma definição de língua de forma consistente e coesa ao longo de todo o texto, para, dessa forma, garantir uma orientação mais precisa dos currículos escolares e promover a educação básica de forma igualitária em todo país. Sendo assim, considera-se fundamental a análise de outros documentos base, possibilitando uma análise mais detalhada e precisa sobre as concepções de ensino do componente curricular Língua Inglesa inerentes a eles.

Torres \& Terres $\mid$ A língua inglesa na BNCC: uma análise das concepçóes de língua 


\section{REFERÊNCIAS}

AZEVEDO, I. C. M. de; DAMACENO, T. M. do S. S. Desafios do BNCC em torno do Ensino de Língua Portuguesa na Educação Básica. Revista de Estudos de Cultura, n.7, p. 83-92, 2017.

BAKHTIN, M. Estética da criação verbal. Trad. Paulo Bezerra. 6. ed. São Paulo: Editora WMF Martins Fontes, 2011.

BAKHTIN, M. Teoria do romance I: a estilística. Trad. Paulo Bezerra. São Paulo: Editora 34, 2015.

BEZERRA, R. G.; LUNA, T. S. Concepções de linguagem: uma análise preliminar do discurso docente e das práticas em sala de Aula. Encontros de Vista. Recife, v.16, n. 1, p. 31-50, jan./jun. 2016.

BRASIL. Ministério da Educação. Base Nacional Comum Curricular. Brasília: MEC, 2017.

BRASIL. Base Nacional Comum Curricular. Disponível em: http://basenacionalcomum.mec.gov.br/ Acesso em: 14 ago. 2019.

CELCE-MURCIA, M. et al. Teaching pronunciation: a course book and reference guide. 2. ed. Cambridge, UK: Cambridge University Press, 2010.

COELHO, A. L. S.; BELCHIOR, Y. K. A BNCC e a história antiga: uma possível compreensão do presente pelo passado e do passado pelo presente. Mare Nostrum, n. 8. 2017.

CORREA, D. R. A base e o edifício: balanço e apontamentos sobre a fortuna crítica da BNCC. Revista do Lhiste, Porto Alegre, v.4, n.3, p. 80-85, 2016.

CRYSTAL, D. English as a global language. 2. ed. Cambridge: Cambridge University Press, 2003.

DÖRNYEI, Z. Research method in applied linguistics: quantitative, qualitative and mixed methodologies. Oxford: Oxford University, 2007.

FISTAROL, C. F. S.; FISCHER, A.; WENDERLICH, R. C. C. A base nacional comum curricular e a formação de professores de língua inglesa: desafios e possibilidades. RPGE - Revista on line de Política e Gestão Educacional, Araraquara, v. 23, n. 2, p. 341-355, maio/ago., 2019.

GERALDI, J. W. Concepções de linguagem e ensino de português. In: GERALDI, J. W. (org.). O texto na sala de aula: leitura e produção. Cascavel: Assoeste, 1984. p. 41-49.

GIROTTO, E. D. Dos PCNS a BNCC: o ensino de geografia sob o domínio neoliberal. Geo UERJ, Rio de Janeiro, n. 30, p. 419-439, 2017.

GONÇALVES, L. A. de A.; BARONAS, J. E. de A. Concepções de linguagem: gramática de língua portuguesa e ensino de língua materna. Entretextos. Londrina, v.13, n. 2, p. 243-265, jul./dez. 2013.

GONTIJO, C. M. M. Base nacional comum curricular (bncc): comentários críticos. Revista Brasileira de Alfabetização - ABAlf, v. 1, n. 2, p. 174-190, 2015.

Forum lingüístic., Florianópolis, v.18,n.3,p.6466-6478,jul./set.2021 
JENKINS, J. The Phonology of English as an international language. Oxford: OUP, 2000.

LEITE, R. F.; RITTER, O. M. S. Algumas representações de ciência na BNCC - Base nacional comum curricular: área de ciências da natureza. Temas \& Matizes, Cascavel, v. 11, n. 20, p. 1-7, jan./jun., 2017.

LYOTARD, J. F. A condição pós-moderna. Trad. Ricardo Corrêa Barbosa. 17. ed. Rio de Janeiro: José Olímpio, 2018.

MARTINELI, T. A. P. et al. A educação física na BNCC: concepções e fundamentos políticos e pedagógicos. Motrivivência, v. 28, n. 48 , p. $76-95,2016$.

MICARELlO, H. A. L. da S. A BNCC no contexto de ameaças ao estado democrático de direito. EccoS Revista Científica, Universidade Nove de Julho, São Paulo, n. 41, p. 61-75, 2016.

MOLLMANN, M. T. A BNCC na prática: o ensino de língua inglesa pautado por projetos pedagógicos. 2018. 57f. Trabalho de Conclusão de Curso (Bacharelado) - Departamento de Letras. Universidade do vale do Taquari Univates, Lageado, 2018.

MOZENA, E. R., OSTERMANN, F. Sobre a base nacional comum curricular (BNCC) e o Ensino de Física. Caderno Brasileiro de Ensino de Física, v. 33, n. 2, p. 327-332, ago. 2016.

NEIRA, M. G.; SOUZA JÚNIOR, M. A educação física na BNCC: procedimentos, concepções e efeitos. Motrivivência, v. 28, n. 48, p. 188-206. 2016.

NEIRA, M. G.; SOUZA JÚNIOR, M.; ALMEIDA, D. F. de. A primeira e segunda versões da BNCC: construção, intenções e condicionantes. EccoS Revista Científica, Universidade Nove de Julho, São Paulo, n. 41, p. 31-44., 2016.

RAJAGOPALAN, K. The identity of "world english”. In: GONÇALVES, G. R.; ALMEIDA, S. R. G.; PAIVA, V. L M. de O.; RODRIGUES-JÚNIOR; A. S. (org.). New challenges in language and literature. Belo Horizonte, FALE/UFMG, 2009. p. 97-107.

ROCHA, C. F.; DIEZ, X. C. L. A BNCC-em: Dimensões Culturais do Ensino de Língua Inglesa. Estudos de Linguagem, Rio de Janeiro, n. 1. UFF, 2018. Trabalho apresentado no IX Seminário dos Alunos dos Programas de Pós-Graduação do Instituto de Letras da UFF (SAPPIL).

SILVA JÚNIOR, A. F. da. BNCC, componentes curriculares de história: perspectivas de superação do Eurocentrismo. EccoS Revista Científica. n. 41, p. 91-106, 2016.

SILVA, K. M. da; SANTOS, L. I. S.; JUSTINA, O. D. Entrevista Com Kanavillil Rajagopalan:

Ponderações Sobre Linguística Aplicada, Política Linguística E Ensino-aprendizagem. Revista de Letras Norte@mentos - Estudos Linguísticos, Sinop, v. 4, n. 8, p. 75-81, jul./dez. 2011.

SILVA, M. R. da. Currículo, ensino médio e BNCC: Um cenário de disputas. Revista Retratos da Escola, Brasília, v. 9, n. 17, p. 367 379, 2015. Disponível em: http://retratosdaescola.emnuvens.com.br/rde/article/view/586. Acesso em: 15 ago. 2019. 
SILVA, M. R. da. A BNCC da Reforma do Ensino Médio: O Resgate de um Empoeirado Discurso. Educação em Revista. Belo Horizonte, v. 34, 2018.

TRICHES, E. de F.; ARANDA, M. A. de M. A formulação da base nacional comum curricular (BNCC) como ação da política educacional: breve levantamento bibliográfico (2014-2016). Revista Online de Extensão e Cultura Realização, v. 3, n. 5, p. 81-98, 2016.

VOLOCHÍNOV, V. N. A construção da enunciação e outros ensaios. São Carlos: Pedro \& João Editores, 2013.

VOLOCHÍNOV, V. N. Marxismo e filosofia da linguagem: problemas fundamentais no método sociológico na ciência da linguagem. Trad. Sheila Grillo e Ekaterina Vólkova Américo. 2.ed. São Paulo: Editora 34, 2018.

XAVIER, A. C.; CORTEZ, S. (org.). Conversas com lingüistas: virtudes e controvérsias da lingüística. São Paulo: Parábola Editorial, 2003.

\section{$($ (1) $\circledast \circledast$}

